\title{
Avaliação de advertências: Contribuições do design da informação para avaliação de eficácia comunicacional de rotulagem nutricional frontal
}

Warning assessment: Information design contributions

to the evaluation of communication efficacy

of front of packaging nutrition labelling

Carlos Felipe Urquizar Rojas, Carla Galvão Spinillo. 
Rojas, C. F. U. \& Spinillo, C. G. | Avaliação de advertências: Contribuições do design da informação para avaliação de eficácia comunicacional de rotulagem nutricional frontal

advertências, rotulagem nutricional, comunicação

Warnings, nutrition labelling, communication
No contexto da nutrição e saúde pública, pesquisadores têm avaliado a eficácia de rótulos de advertência nutricional frontal com intuito de orientar políticas de regulamentação. Entretanto, seus estudos têm pouco enfoque para aspectos gráficos do design de advertências que podem influenciar atenção, legibilidade, compreensão e processamento da informação dos consumidores. Considerando isto, este artigo apresenta uma meta-análise de 11 artigos selecionados na revisão sistemática da chamada nำ17/2017 CNPq/ANVISA na qual foram (a) identificados testes empregados em pesquisas que avaliaram a eficácia comunicacional de rótulos de advertência nutricional frontal, e (b) estabelecidas possíveis relações com as etapas do modelo de comunicação e processamento de informação de advertência (C-HIP Model). Este consta das etapas: mudança de atenção, manutenção de atenção, compreensão e memória, crenças e atitudes, motivação e comportamento. Os resultados indicaram: predominância em testes sobre intenção de comportamento e percepção de saudabilidade; enfoque nas fases finais do C-HIP model e pouca atenção a aspectos do design da informação dos rótulos de advertência. Conclui-se que existem lacunas entre pesquisas na área de nutrição, sobre fatores inerentes ao design e processamento da informação de advertência, demandando assim futuras investigações.

In the context of nutrition and public health, researchers have evaluated the effectiveness of front of package nutrition warning labels to guide regulatory policies. Their studies little have focused on graphic aspects of warning design that may influence attention, legibility, understanding and processing of information by consumers. Considering this, a meta-analysis of 11 articles selected from the systematic review of the call No. 17/2017 CNPq/ANVISA is presented here. The meta-analysis aimed to (a) identify tests used in studies that evaluated the communication efficacy of front of package nutrition warning labels, and (b) to establish their possible relations to the stages of the communication human information processing model for warnings (C-HIP Model). It includes the following phases: attention switch, attention maintenance, comprehension and memory, attitudes and beliefs, motivation and behavior. The results indicated: predominance of tests on behavioral intentions and healthfulness perception; focus on the final phases of the C-HIP Model and less attention to aspects about information design in warning labels. It is concluded that there are gaps in nutrition research area about factors associated to the design and processing of warning information, thus demanding future investigations.

\section{Introdução}

$\mathrm{Na}$ área da saúde, o tema de advertências nutricionais ganha ênfase a partir de 2015, com a implantação do primeiro modelo de rotulagem de advertência nutricional no Chile, o qual seguiu recomendações de organizações internacionais de saúde (Reyes, 2019; Reyes et al, 2020; Hargous et al, 2020). Essas recomendações são respostas ao aumento da má nutrição mundial, pandemia de obesidade e doenças crônicas não transmissíveis (DCNT), como as doenças cardiovasculares, 
alguns tipos de câncer, diabetes e hipertensão (Monteiro et al, 2010; Popkin, Adair \& Ng, 2012). Para ilustrar a gravidade da situação de saúde mundial, tem -se que as DCNTs matam mais de 41 milhões de pessoas por ano, representando $71 \%$ de todas as mortes globais (Paho, 2015). Assim, organizações internacionais da saúde recomendam aos governos, entre outras medidas, a melhoria das informações nutricionais para levar as populações dos países a escolhas alimentares mais saudáveis (Paho, 2015; Who, 2017). Consequentemente, vários países discutem a adoção de tipos de rótulos nutricionais frontais (Fao,1996; Who, 2017; Paho, 2015), dentre eles o rótulo de advertência.

No Brasil, a ANVISA - Agência Nacional de Vigilância Sanitária (2018) conduz desde 2014 o processo regulatório para implantação de um novo modelo de rotulagem nutricional para alimentos e bebidas. Neste sentido, diversos documentos foram produzidos como marcos do processo de regulação brasileiro, tais como:

- Relatório Preliminar de Análise de Impacto Regulatório sobre Rotulagem Nutricional da ANVISA (2018).

- Documento de Revisão Sistemática: Modelos de rotulagem nutricional frontal de alto conteúdo de nutrientes críticos comparado a outros modelos de rotulagem frontal nutricional (Silva, 2019) chamada CNPq/ANVISA no 17/2017.

- Relatório de consolidação das Consultas Públicas no 707 e 708/2019 da ANVISA.

- Proposta de modelo de Rotulagem Nutricional para o Brasil do Instituto Brasileiro de Defesa do Consumidor (IDEC) e LabDSILaboratório de Design de Sistemas de Informação da UFPR (2017).

Para orientar processos regulatórios e políticas públicas em nutrição e saúde, pesquisadores vêm realizando estudos para avaliar a eficácia dos rótulos nutricionais frontais e rótulos nutricionais frontais de advertência (Minsal, 2009a; Kelly et al, 2009; Borgmeier \& Westenhoefer, 2009; Inta, 2012; Ares et al, 2016; Idec, 2016; Talati et al, 2016; Khandpur et al, 2018). Vale salientar que, no âmbito dos estudos sobre mensagens de advertências, fatores da sua representação gráfica que influenciam a atenção e compreensão dos usuários têm sido pesquisados e reconhecidos como fundamentais para a eficácia e eficiência deste tipo de mensagem (Rogers, Lamson \& Rosseau, 2000; Wogalter, Conzola, Smith-Jackson, 2002; Mont'alvão, 2002; Laughery \& Wogalter, 2014). Entretanto, aspectos gráficos de rótulos nutricionais de advertência (e.g., formato, relação figura-fundo, contorno visual) ainda não são devidamente enfocados nos estudos na área de nutrição, apesar de seu papel relevante como fatores influenciadores de atenção, legibilidade e compreensão da informação pelos consumidores.

Por ouro lado, no âmbito do design da informação, ainda são escassos os estudos sobre rotulagem nutricional de advertências, particularmente os que enfocam a avalição da eficácia da representação gráfica da informação. Como exemplos de estudos nesta área no Brasil, tem-se os conduzidos por Oliveira (2015) 
e Falkenburger e Scoz (2019). O primeiro aponta problemas de legibilidade de informação nutricional em rótulos de alimentos e sugere contribuições do design da informação sobre este tema. Já o estudo de Falkenburger e Scoz (2019) apresenta uma análise de advertências em embalagens de alimentos ultraprocessados do ponto de vista da semiótica com análise do discurso. Assim, percebe-se a necessidade de mais estudos em design da informação com foco na avaliação de rótulos nutricionais de advertências.

No intuito de contribuir para o preenchimento desta lacuna, é apresentado aqui um estudo em design da informação que discute aspectos metodológicos de pesquisas sobre avaliação de rotulagem nutricional de advertências. O estudo visou identificar métodos/ técnicas empregados em pesquisas que avaliaram a eficácia comunicacional de rotulagens frontais de advertências, e estabelecer sua conformidade com etapas da comunicação de advertências adotados no C-HIP model (Communication- Human Information Processing). Para contextualizar o tema antes de apresentar o estudo, são introduzidos a seguir a definição, componentes e métodos de avaliação de advertências, e na sequência conceitos e classificações de rotulagem nutricional.

\section{Advertências na comunicação de informações de riscos}

Advertências são estímulos de alerta direcionados ao usuário e visam despertar um processo de busca de informação para um comportamento seguro a fim de minimizar ou evitar riscos (e.g., Lehto, 1992; Edworthy, 1996; Mont'alvão, 2002; Laughery, 2006; Pettersson, 2020; Laughery \& Wogalter, 2014). Portanto, advertências não eliminam riscos (e.g., Edworthy, 1996; Wogalter, Dejoy \& Laughery, 1999). Como ferramentas de comunicação de risco, advertências devem ser breves e sinalizar: a natureza dos riscos (hazard), sua probabilidade (risk) e a magnitude do perigo (danger) (Laughery \& Hammond, 1999). Utilizam ainda diferentes modos de representação da informação - como modo verbal (textos de alerta) e pictórico (símbolos, pictogramas) - e tipos de linguagens, como proibitiva e não proibitiva (Edworthy, 1996; Pettersson, 2020). Assim, de acordo com a literatura (e.g., Edworthy, 1996; Wogalter, 2018; Laughery, 2006; Wogalter \& Mayhorn, 2017; Wogalter et al, 2017) para cumprir seu objetivo comunicacional as advertências devem:
a. atrair a atenção e ser legíveis
b. alertar, comunicar e fornecer informação sobre riscos,
c. promover segurança
d. ser facilmente compreendida e orientar decisões
e. ajudar a lembrar ou ser memorizada
f. permitir julgamentos e
g. conferir credibilidade
h. influenciar e motivar para um comportamento seguro. 
Além dos aspectos acima colocados, Laughery e Hammond (1999) problematizam dois propósitos poucos discutidos das advertências: a transferência de responsabilidade e a garantia do direito à informação. A primeira trata dos aspectos legais de isenção de responsabilidade da indústria sobre possíveis riscos após apresentar uma advertência ao usuário. Já a garantia do direito à informação trata do direito do usuário em ser informado sobre todos os riscos envolvidos no uso de um produto, mesmo que eles sejam pequenos e pouco prováveis de acontecer.

Dessa forma, para fornecer informações que ajudem o usuário a reconhecer o risco, as possíveis consequências negativas e as ações seguras que podem ser tomadas para evitar o risco (WOGALTER, 2017), instituições buscam normatizar as advertências. Dentre as normas vigentes se destacam a ANSI Z535 e ISO 3864. Para ANSI, uma advertência deve informar o tipo de risco, a seriedade do risco, a consequência do envolvimento das pessoas com o risco e como evitá-lo.

Assim, as advertências geralmente apresentam as mensagens por meio dos componentes informacionais descritos nas normas da ISO 3864 e ANSI Z535: (a) palavra-chave, (b) natureza do risco, (c) consequência e (d) instrução. Os componentes da advertência buscam atender às necessidades informacionais do usuário frente ao risco. Por exemplo: a palavra-chave, que alerta para o tipo de risco (e.g., Atenção, Perigo) possibilita ao usuário inferir sobre o grau de gravidade do risco. Por sua vez, ao alertar da natureza do risco (e.g., alto conteúdo de sódio, açúcar e gorduras) informa de que se trata o risco. Já o componente consequência avisa as implicações do não atendimento à advertência (e.g., risco de desenvolver doenças crônicas não transmissíveis). Por fim, a instrução sobre o procedimento seguro empodera o usuário para evitar o risco (e.g., minimizar ou evitar o consumo de alimentos/bebidas com nutrientes críticos em excesso).

De forma ideal estes componentes devem estar presentes na advertência. Porém, dependendo da situação de risco e do artefato que veicula a advertência (e.g., tamanho reduzido de rótulos em embalagens), é possível a não inclusão de alguns destes componentes. Vale salientar que, além desses componentes, as cores são padronizadas conforme o tipo e seriedade do risco. A cor vermelha é indicada para perigo, a cor laranja e a cor preta para advertência, a amarela para cuidado (ANSI Z535-4). No entanto, segundo Wogalter (2018), mesmo com o uso de cores, os usuários tendem a não perceber a diferença de seriedade entre as palavras-chave 'advertência' e 'cuidado'. Como exemplo de um artefato de advertência apresentando os componentes indicados pela ANSI Z535 tem-se a placa de Warning high voltage na figura 1. 


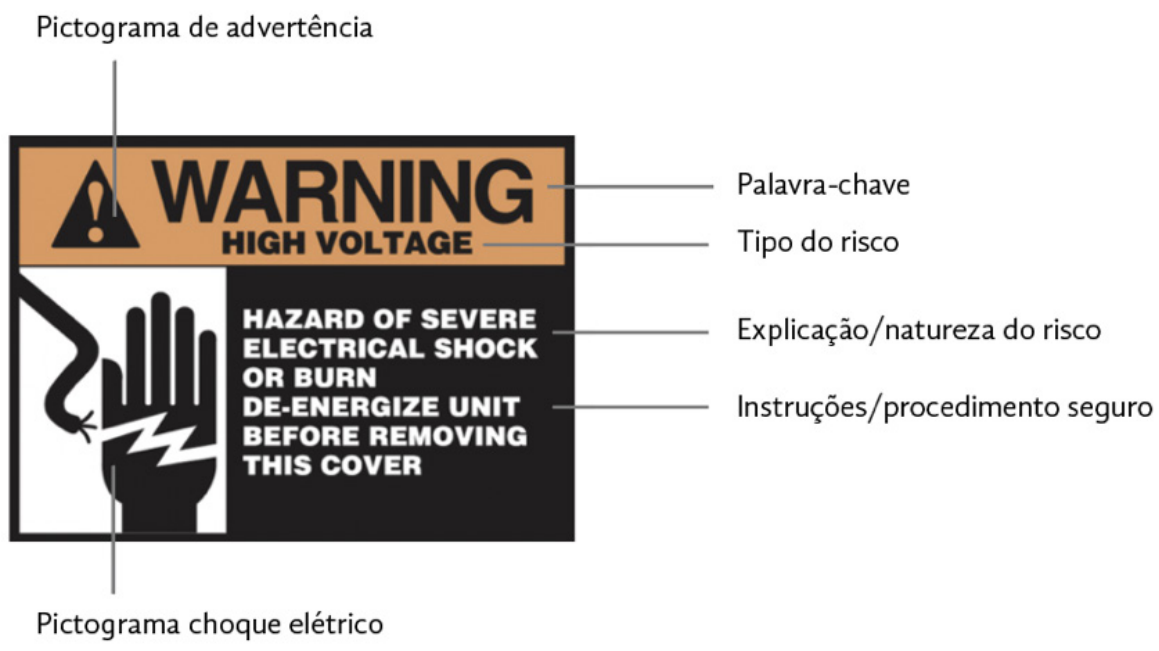

Figura 1 Elaborado pelos autores com base no exemplo da ANSI Z535

\subsection{Fatores que influenciam a eficácia comunicacional das advertências}

Estudos de revisão de literatura têm buscado analisar os fatores que influenciam a eficácia comunicacional das advertências. Alguns autores buscam integrar fatores a etapas de modelos de comunicação de informação (e.g., Rogers, Lamson \& Rosseau, 2000; Wogalter, Conzola \& Smith-Jackson, 2002; Laughery \& Wogalter, 2014), enquanto outros compilam os fatores influenciadores da eficácia de advertências de forma não hierárquica (e.g., Parsons, Seminara \& Wogalter 1999). Além disso, diferentes termos e nomenclaturas são utilizados para se referir a fatores equivalentes ou complementares entre si, como por exemplo 'familiaridade' e 'conhecimento prévio'. O quadro a seguir apresenta extensa lista de fatores compilados da literatura (e.g., Rogers, Lamson \& Rosseau, 2000; Wogalter, Conzola \& Smith-Jackson, 2002; Laughery \& Wogalter, 2014; Parsons, Seminara \& Wogalter, 1999). Estes foram organizados em três grupos: (a) fatores referentes ao contexto em que a advertência se apresenta (e.g., ruídos, distrações do ambiente, facilidade de ser visualizado no ambiente); (b) fatores no âmbito do usuário/receptor da mensagem de advertência (e.g., visão, familiaridade); e (c) fatores referentes ao design das advertências (e.g., simplicidade/complexidade gráfica, uso de bordas/ cercamento). O quadro a seguir mostra esta classificação, tornando possível constatar que os fatores de design se encontram em maior número que os demais grupos, o que vem a indicar a relevância de aspectos do design da informação na comunicação de advertências. 
Rojas, C. F. U. \& Spinillo, C. G. | Avaliação de advertências: Contribuições do design da informação para avaliação de eficácia comunicacional de rotulagem nutricional frontal

\begin{tabular}{|c|c|c|}
\hline Fatores do contexto: & Fatores dos usuários & Fator do design das advertências: \\
\hline $\begin{array}{l}\text { Custo da conformidade } \\
\text { Facilidade de visualização } \\
\text { Localização Modelagem/exemplificação } \\
\text { (pessoas) } \\
\text { Ruído e distrações } \\
\text { Periculosidade do risco } \\
\text { Custo do comportamento }\end{array}$ & $\begin{array}{l}\text { Conhecimento prévio Compreensão de } \\
\text { símbolos Controle de percepção } \\
\text { Crença e concordância } \\
\text { Cultura e etnia } \\
\text { Deficiências visuais e visão Familiaridade } \\
\text { Gênero } \\
\text { Idade } \\
\text { Intenção de busca } \\
\text { Intenções de compra Memorização } \\
\text { Responsabilidade e estilo individual } \\
\text { Stress } \\
\text { Treinamento } \\
\text { Percepção de risco } \\
\text { Treinamento }\end{array}$ & $\begin{array}{l}\text { Alarme e Som } \\
\text { Borda/cercamento } \\
\text { Brevidade/comprimento do texto } \\
\text { Uso de termos conhecidos } \\
\text { Redação, tom } \\
\text { Simplicidade/Complexidade } \\
\text { Contraste e cor } \\
\text { Credibilidade } \\
\text { Declaração de risco } \\
\text { Explicitação e clareza } \\
\text { Estilo de tipografia } \\
\text { Formato } \\
\text { Uso de fotografias } \\
\text { Uso de pictogramas } \\
\text { Tipo de impressão } \\
\text { Layout e design } \\
\text { Localização } \\
\text { Uso de palavra-sinal } \\
\text { Uso de orientação } \\
\text { Variações de advertências } \\
\text { Saliência } \\
\text { Formato } \\
\text { Tamanho geral } \\
\text { Tamanho da fonte } \\
\text { Informação de consequências } \\
\text { Interatividade } \\
\text { Facilidade de visualização } \\
\text { Modelagem/exemplificação } \\
\text { (imagem ou pictograma) }\end{array}$ \\
\hline
\end{tabular}

Quadro 1 Fatores que influenciam a eficácia das advertências.Fonte: Elaborado pelos autores com base em Rogers, Lamson e Rosseau (2000); Wogalter, Conzola e Smith-Jackson (2002); Laughery e Wogalter (2014); Parsons, Seminara e Wogalter (1999).

Somados a esses fatores, Laughery e Hammond (1999) propõem quatro princípios que consideram os usuários no desenvolvimento de advertências eficazes, os quais implicam nas seguintes ações:

1. Conhecer o usuário (receptor da advertência). Estudos sobre o perfil e necessidades informacionais dos usuários exigem investimento, mas fornecem melhores resultados.

2. Projetar para quem tem maior dificuldade, contempla mais usuários. A advertência deve ser projetada para ser acessível aos usuários com maior limitação em perfil (e.g., baixo grau de escolaridade ou baixa visão), assim também será acessível para os demais usuários.

3. Projetar como sistema contempla mais tipos de usuários. Conceber sistemas de advertência com diferentes componentes/artefatos para atender diversidade de grupos de usuários que possam estar expostos ao risco (e.g., médico, paciente).

4. Realizar testes em ambientes reais promovem eficácia na avaliação. Testes em ambiente real com uma amostra 
representativa do público-alvo são mais efetivos para avaliar compreensão e comportamento dos usuários.

Os princípios da literatura, assim como os fatores para desenvolvimento de advertências são também pertinentes ao design de advertências para rotulagem nutricional. Isto pois os rótulos nutricionais de advertência visam informar sobre riscos à saúde no consumo de produtos com nutrientes críticos em excesso.

Considerando a literatura sobre advertências, fica evidente que para averiguar a eficácia comunicacional de rótulos nutricionais de advertência faz-se necessário adotar métodos, dimensões e métricas de avaliação condizentes com este tipo de mensagem, assim como averiguar de que forma usuários/consumidores percebem e compreendem as informações. Neste sentido, nos tópicos a seguir são apresentados alguns fatores de processamento de informação que norteiam a avaliação de advertências a partir do C-HIP model (Communications-Human Information Processing).

\section{O C-HIP Model (Communications-Human Information Processing)}

Diversos modelos sobre comportamento comunicacional têm sido propostos procurando responder, por diferentes perspectivas, como os usuários percebem o risco e como a percepção de risco influencia a aceitação das advertências e a mudança de comportamento. Dentre eles, destaca-se o modelo proposto por Wogalter (2018): C-HIP model (Communications-Human Information Processing) por ser amplamente empregado em pesquisas sobre advertências (e.g., Mont'alvao, 2000; Wogalter, Conzola e Smith-Jackson, 2002; Laughery, 2006; Wogalter 2006; Wogalter, 2019; Peterson, 2020). Este modelo vem sendo aprimorado por Wogalter (2018) e seu grupo de pesquisa desde 1996 (Lauguery \& Wogalter, 1996) como um modelo estruturado de comunicação com detalhamento do processamento cognitivo não linear do receptor/usuário.

O C-HIP model estrutura as etapas do processo de comunicação de advertências como: Fonte/Emissor da mensagem (e.g., agência

1 Tradução livre para: source, channel, other stimuli, delivery, receiver, attention switch, attention maintenance, comprehension and memory, attitudes and Beliefs, motivation e behavior. reguladora); Canal de veiculação da mensagem (e.g., visual, auditivo); Entrega: forma de representação da mensagem (e.g., rótulo impresso, pictograma) a qual pode ser afetada por Estímulos do ambiente (e.g., iluminação, ruídos); e etapas referentes ao Receptor da mensagem de advertência. Estas referem-se ao processamento cognitivo do receptor, sendo estas: Mudança de atenção: a advertência chama a atenção do receptor; Manutenção da atenção: o receptor mantém-se atento à advertência; Compreensão e Memória: a advertência é entendida e memorizada; Crenças e atitudes: a advertência é condizente com o perfil cultural do receptor quanto ao que considera ser crível e factível; Motivação: o receptor é motivado a cumprir/atender à advertência; e 
por fim Comportamento: o receptor muda seu comportamento frente ao risco informado na advertência.

O gráfico a seguir ilustra o C-HIP model, destacando em cor verde as etapas referentes ao receptor. Segundo Wogalter (2018), as etapas do C-HIP model são encadeadas de forma linear com possibilidade de volta cíclica, estando a eficácia comunicacional vinculada ao sucesso de todas as etapas. Assim, a falha em uma etapa pode causar um 'gargalo' e comprometer o resultado das etapas seguintes e do comportamento final do receptor. Pesquisadores consideram que $o$ modelo pode auxiliar na avaliação da eficácia das advertências por meio da identificação das falhas da advertência (e.g., WOGALTER, DEJOY \& LAUGHERY, 1999; WOGALTER, 2006, 2017, 2018).

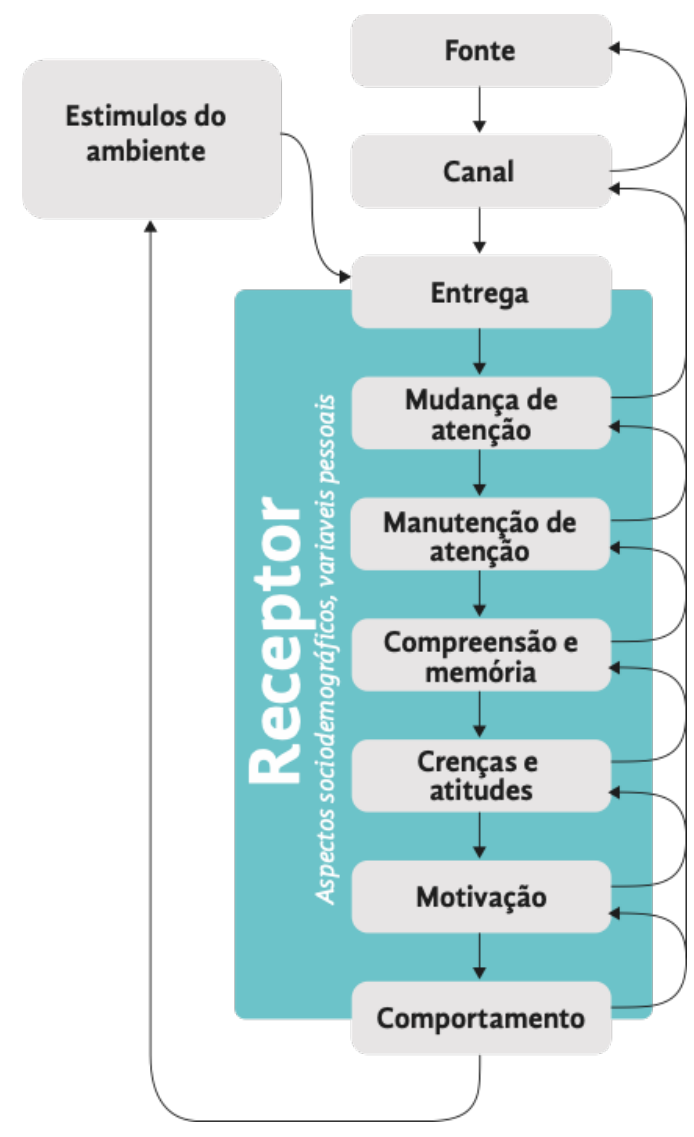

Gráfico 1 C-HIP model. Fonte: Elaborado e traduzido pelos autores com base em Wogalter (2018)

\subsection{A avaliação das advertências e o C-HIP model}

Historicamente a avaliação de advertências tem sido foco de estudos nas áreas da ergonomia informacional e fatores humanos. Um número significativo de pesquisas sobre questões de design das advertências encontra-se no período entre 1970 e o fim da década de 1990. Estas resultaram em princípios, diretrizes e modelos utilizados até hoje, 
tornando este período de grande importância para o design de advertências. Inicialmente foram estudadas as questões gráficas sobre localização, tamanho, cor, legibilidade e redação das palavras sinais. Em meados da década de 80 foram estudados os fatores que influenciam a eficácia das advertências com a inclusão da intenção de mudança de comportamento dos usuários (LAUGHERY \& HAMMOND, 1999). Este último mereceu e tem merecido especial atenção de pesquisadores, visto que mudar o comportamento do usuário frente ao risco é o grande desafio e meta do design de advertência. Neste sentido, o C-HIP model pode servir para auxiliar a avaliar e identificar o locus de problemas comunicacionais das advertências, particularmente nas etapas referentes ao Receptor/ usuário, como mencionado anteriormente. Dessa forma, é possível relacionar as etapas do modelo a testes de avaliação das advertências identificados literatura de ergonomia informacional e fatores humanos, conforme a seguir.

Avaliação de atenção

Para avaliar as primeiras etapas do processamento cognitivo do receptor - Mudança e Manutenção de atenção - Wogalter, DeJoy \& Laughery (1999) recomendam os seguintes testes:

- Teste de classificação (ranking) verifica o grau de saliência e capacidade de chamar a atenção através da hierarquização de diferentes desenhos de advertências.

- Teste de legibilidade/saliência verifica o quão legíveis e visíveis os desenhos de advertências estão em diferentes distâncias e condições ambientais (e.g., luz, tamanho, localização e tempo de exposição).

- Teste de atenção por meio da memória verifica o quanto os participantes recordam a advertência, relativo à sua saliência, em determinado local e/ou situação passados.

- Rastreamento ocular (eye-tracking) verifica com que frequência e intensidade o movimento dos olhos é atraído para a advertência.

- Medição do tempo de reação verifica a velocidade de resposta ao estímulo da advertência.

Avaliação de compreensão e memória

Na etapa consecutiva, de avaliação de Compreensão e Memória, Young e Lovvoll (1999), Wogalter, DeJoy e Laughery (1999) argumentam que a compreensão de textos e de imagens pode ser avaliada isoladamente. Assim, para compreensão dos textos os autores indicam:

- Teste de conhecimento prévio verifica o repertório dos participantes, sendo recomendado sua condução antes do desenvolvimento das advertências. 
- Teste de leiturabilidade (Readability) verifica a facilidade de entender o que está escrito, considerando o esforço cognitivo dos participantes e seu perfil.

- Teste de coerência verifica se palavras e sentenças estão organizadas de forma coerente.

- Teste de coerência com rastreamento ocular verifica se os participantes leram a mensagem mais de uma vez ou em outro sentido para entender a advertência.

Para avaliar a compreensão das imagens, Young e Lovvoll (1999) recomendam:

- Teste de compreensão de elementos pictóricos verifica o significado associado a símbolos/imagens por partes dos usuários, podendo ser conduzidos em ambientes controlados ou em contexto real.

- Teste de compreensão e verificação da origem dos símbolos examina a adequabilidade de símbolos de um contexto cultural quando aplicado a outro contexto (WOGALTER, 2006; WOGALTER, DEJOY \& LAUGHERY, 1999; YOUNG \& LOVVOLL, 1999).

Também é comum avaliar como a memória atua nas diferentes etapas de um modelo de informação de advertência (YOUNG \& LOVVOLL, 1999), sendo para isto empregados:

- Teste de memória (recall) verifica se os participantes lembram da advertência apresentada.

- Teste de reconhecimento avalia se os participantes reconhecem elementos da advertência. Também é comum avaliar o tempo de reconhecimento e lembrança das advertências vistas após realização de uma tarefa.

- Teste de match verifica a relação de pertinência entre texto e elemento pictórico da advertência

- Teste de complementação de textos verifica se os participantes lembram ou inferem os termos faltantes em um texto de advertência.

- Teste de complementação de imagens verifica se os participantes lembram ou inferem os elementos/partes faltantes em uma imagem de advertência no contexto em que estava aplicada.

Avaliação de crenças e atitudes, e motivação

Segundo Wogalter (2018), as etapas de crenças e atitudes englobam desde as formas de pensar um assunto até o comportamento do usuário. A atitude está relacionada à percepção de risco e a chance de sofrer uma lesão (EDWORTHY, 2000). A percepção de risco é um constructo multivariável composto por: familiaridade com o produto ou situação, familiaridade com o risco, noção de probabilidade do dano e gravidade do possível prejuízo (YOUNG \& LOVVOLL, 1999). Assim, segundo Wogalter (2018) e, Young e Lovvoll (1999) as formas comuns de mensurar a percepção de risco são: 
- Avaliação de percepção de risco verifica o impacto de diferentes termos, cores e formas das advertências na maneira como usuário percebe o risco.

- Ranking de risco percebido verifica a percepção de grandeza associada ao risco através de hierarquização de produtos de acordo com a percepção de risco.

- Avaliação de custo de concordância verifica o quanto e por quais motivos o participante adotaria o comportamento seguro diante do risco e advertência.

- Avaliação da crença verifica valores e aspectos subjetivos dos participantes referentes ao controle do risco e da credibilidade da advertência.

Além disso, as avaliações de percepção de risco também são úteis para alinhar as percepções do emissor com o receptor da mensagem de advertência, ou seja, podem mostrar que a relação entre o risco percebido (subjetivo) e o risco mensurado (objetivo). Vale salientar que as crenças e atitudes têm relação direta com a motivação para aceitar e valorizar a informação da advertência. Devido a isto, os testes mencionados foram também considerados na etapa de motivação.

Avaliação de comportamento

$\mathrm{Na}$ última etapa do modelo de processamento, comportamento, por questão ética os participantes não são expostos a situações reais de risco. Dessa forma, para avaliar comportamento geralmente são aplicados: avaliação de intenção de comportamento, avaliação de comportamento em ambiente virtual, ou são analisados indicadores físicos (e.g., quantidade de produtos usados) e análises de dados epidemiológicos (e.g., relatórios de internações ou mortes após implantação de advertências) (Wogalter \& Dingus, 1999; Wogalter, Dejoy \& Laughery, 1999; Wogalter, 2018). O gráfico a seguir mostra síntese dos testes mencionados e seu alinhamento às etapas do C-HIP model. 
Rojas, C. F. U. \& Spinillo, C. G. | Avaliação de advertências: Contribuições do design da informação para avaliação de eficácia comunicacional de rotulagem nutricional frontal

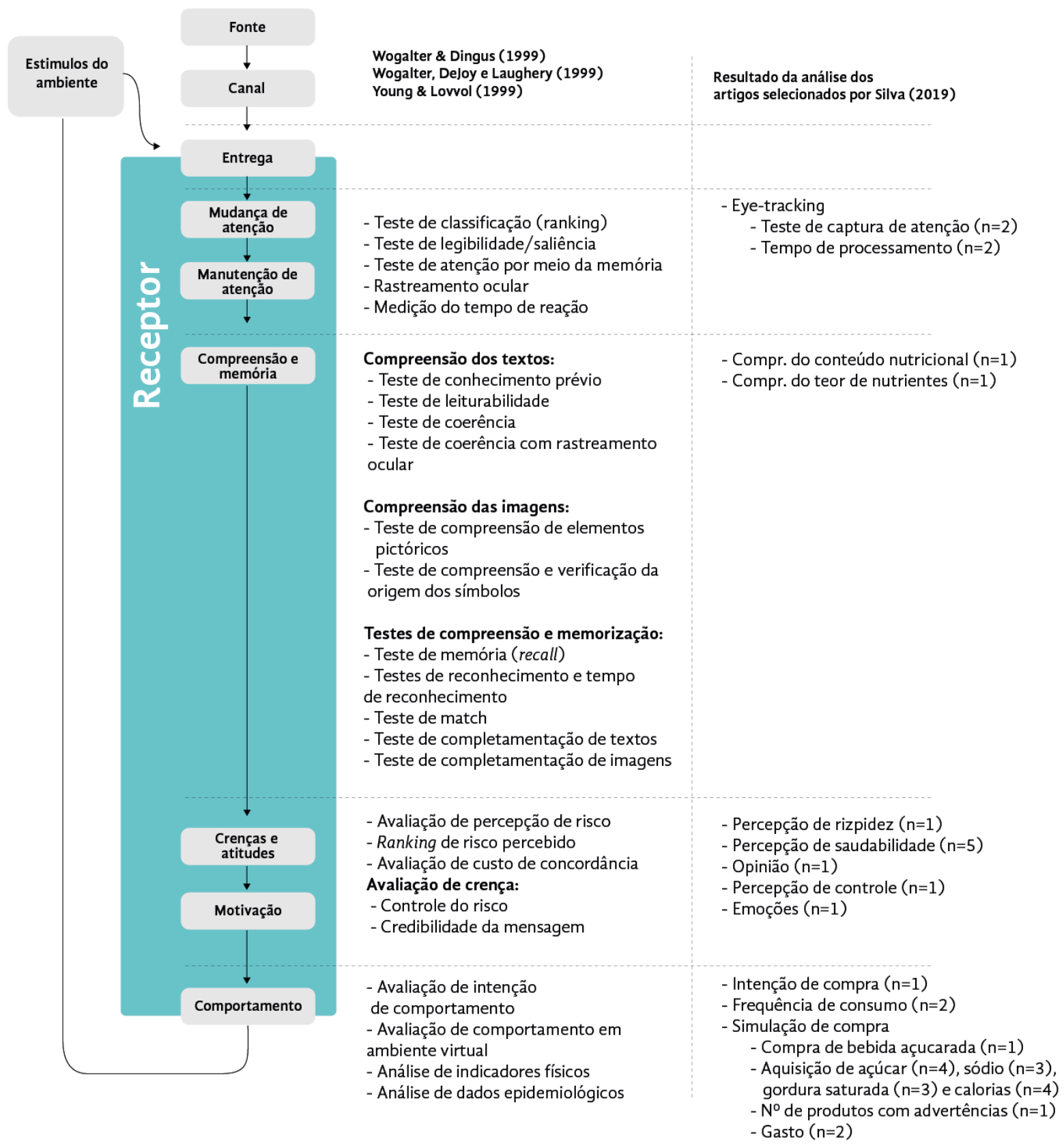

Gráfico 2 Síntese das avaliações de advertências nas etapas do C-HIP model.

Fonte: Elaborado pelos autores com base em Wogalter e Dingus (1999);

Wogalter, DeJoy e Laughery (1999); e Young e Lovvol (1999) 
Os testes, como os citados, que mensuram a eficácia comunicativa de advertências para iniciar um processo de busca de informação e comportamento seguros dos usuários são pertinentes e importantes para a avaliação de rotulagem nutricional de alerta sobre riscos à saúde. O enfoque em questões específicas do design da advertência e no processamento da informação de risco referentes a nutrientes críticos em excesso em alimentos e bebidas podem contribuir para minimizar e até evitar fatores de risco à saúde (e.g., má nutrição, obesidade, doenças crônicas não transmissíveis). Considerando isto, o próximo tópico deste artigo trata de rotulagem de alimentos com enfoque nos rótulos nutricionais frontais de advertência.

\section{Rotulagem de alimentos}

Estudos constatam que indivíduos em geral têm dificuldade de entender as informações nutricionais contidas em embalagens de alimentos e bebidas, e dedicam cada vez menos tempo e atenção no preparo e escolha de alimentos (e.g., Cowburn \& Stockley, 2005; Van Kleef \& Dagevos,2015; Eufic, 2017). Considerando isto, os rótulos nutricionais frontais podem ajudar a comunicar rapidamente informações nutricionais importantes para orientar boas escolhas alimentares (Hodgkins, et al. 2012; Van Kleef \& Dagevos, 2015; Anvisa, 2018).

Os rótulos nutricionais frontais são informações que complementam as declarações nutricionais e, dependendo do país, podem se dar de forma obrigatória ou voluntária. Isto por meio de diferentes abordagens de informação sobre nutrientes relevantes para que os cidadãos façam escolhas alimentares mais saudáveis (e.g., Emrich, Arcand \& Lábbé, 2012; Hawley, Et Al, 2013; Informas, 2017; World Cancer Research Fund International, 2019, Lima et al, 2019; Spinillo, 2019). Do ponto de vista do design da informação, os rótulos nutricionais frontais são artefatos gráficos que destacam e simplificam informações nutricionais importantes, reduzindo a carga cognitiva, visto que as compras de alimentos e bebidas geralmente são decididas pelos consumidores na gôndola do mercado em até três segundos (Emrich, Arcand \& Lábbé, 2012; Spinillo, 2019). Em síntese: rótulos nutricionais frontais devem ser úteis, chamar a atenção e ser fáceis de entender por uma diversidade de consumidores, de diferentes níveis de escolaridade, profissões e idade (Hawley et al, 2013; van Kleef \& Dagevos, 2015).

Do ponto de vista legal, a implementação de um rótulo nutricional frontal faz parte de políticas públicas de saúde que buscam a melhoria do ambiente alimentar (ACTON et al, 2019; ANVISA, 2018). Tais políticas têm como objetivo encorajar a indústria de alimentos e bebidas a adequar ou até reformular seus produtos para que sejam mais saudáveis aos consumidores (van Kleef \& Dagevos, 2015). Políticas públicas contemplando rótulos nutricionais frontais têm 
se dado em diferentes abordagens e experiências regulatórias ao redor do mundo nas últimas décadas. Considerando uma abordagem cronológica, os rótulos são classificados como rótulos de primeira geração: aqueles implementados entre 1989 a 2014; e rótulos de segunda geração: aqueles implementados ou propostos a partir de 2015 (Hodgkins, et al. 2012; Kanter, Vanderlee \& Vandevijvere, 2018). Os rótulos nutricionais frontais de advertência se encontram, portanto, na segunda geração, destacando-se aqui o 'Octógono' implementado pelo Chile no ano de 2016. A figura a seguir mostra os modelos de rótulos frontais considerados de primeira e segunda gerações, conforme apresentados no documento da ANVISA (2018).

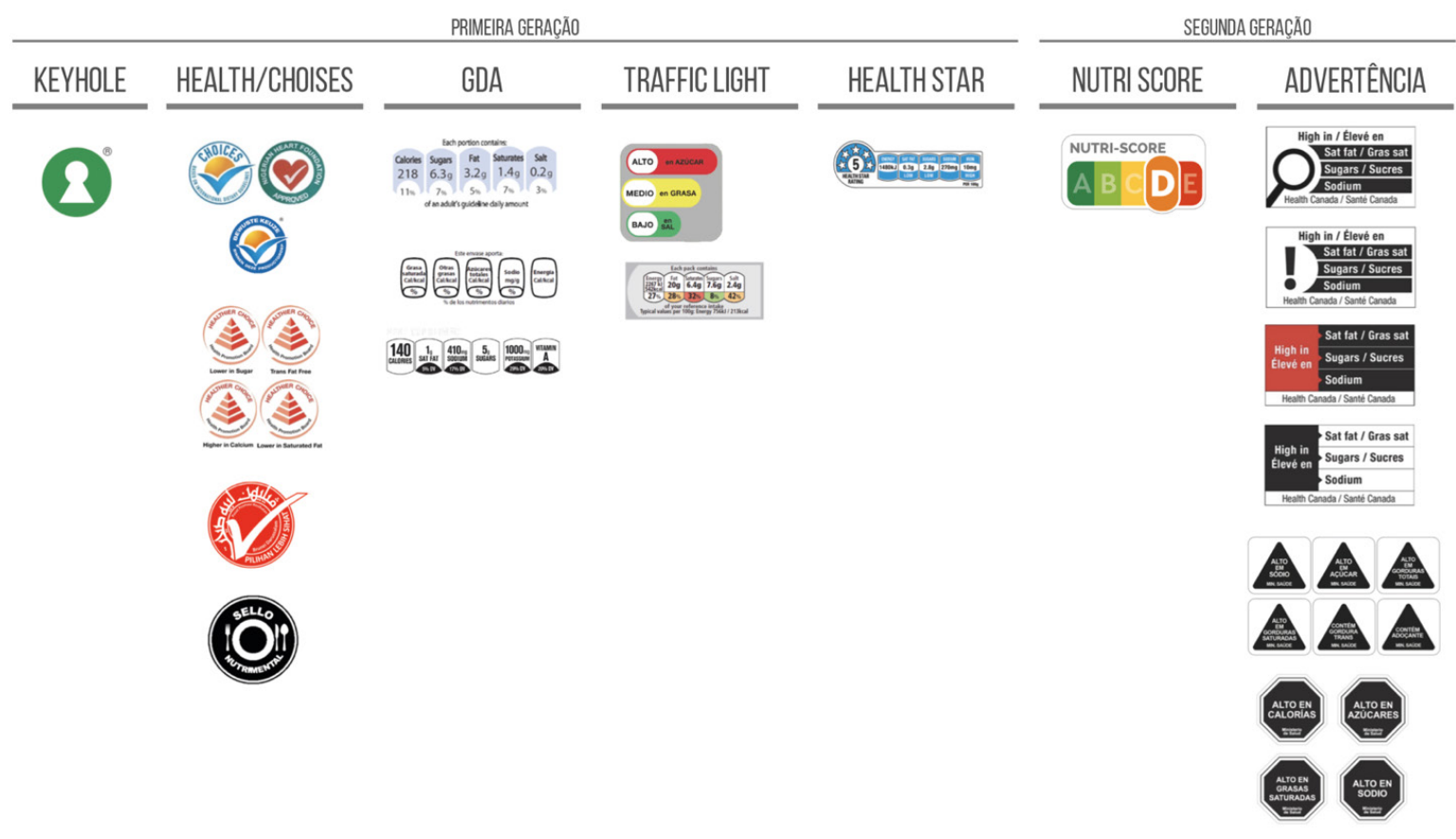

Figura 2 Rótulos nutricionais frontais. Fonte: Elaborado pelos autores com base em ANVISA (2018), Ministério da Saúde do Brasil, Chile, Uruguai, Canadá, Nova Zelândia e Austrália.

Em relação à descrição de rótulos nutricionais frontais, estes podem ser classificados quanto: (a) apresentação, (b) tipo de mensagem e (c) foco nos nutrientes. A primeira categoria diz respeito aos aspectos gráficos dos rótulos nas embalagens, como formas, cores, tamanho e localização. A categoria de tipo de mensagem refere-se a rótulos de contraindicação, de recomendação, e ainda a combinação de ambos. Já o foco nos nutrientes refere-se a rótulos que apresentam nutrientes críticos que implicam em risco à saúde (e.g., sódio, açúcar, gordura saturada); nutrientes positivos à saúde, e a combinação de ambos (Kanter, Vanderlee \& Vandevijvere, 2018; Van Der Bend \& Lissner,2019).

Além disso, uma característica comum a alguns rótulos nutricionais frontais é o uso de elementos e símbolos gráficos 
(van Kleef \& Dagevos, 2015; Spinillo, 2019). Um exemplo disso é o rótulo frontal de advertência proposto pelo IDEC/UFPR para rotulagem nutricional brasileira no documento 'Aprimoramento da informação nutricional nos rótulos de alimentos no Brasil' (IDEC \& UFPR, 2017). Este usa o triângulo como símbolo internacional de advertência para representar o conceito de 'alerta/atenção' (Figura 3), sua apresentação usa a cor preta para indicar advertência e caráter regulatório, sendo seu tamanho proporcional à área da face frontal da embalagem em que se aplica, e sua localização é na parte superior da face da embalagem. O tipo de mensagem é de contraindicação, usando a palavra de alerta 'alto em', e tem foco nos nutrientes críticos.

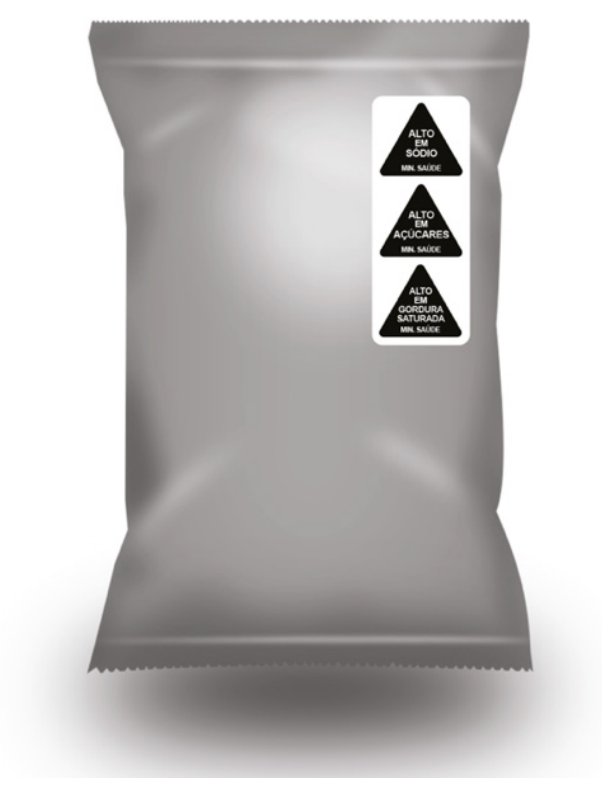

Figura 3 Triangulo de advertência nutricional proposto por IDEC e UFPR (2017). Fonte: Elaborado pelos autores

Considerando os aspectos aqui apresentados e a necessidade de investigação sobre rotulagem frontal de advertência quanto a sua eficácia comunicativa e o processamento da informação, a seguir é apresentado o foco deste artigo: o estudo sobre avaliação de rotulagem nutricional frontal de advertência.

\section{Estudo comparativo sobre avaliação de rotulagem nutricional frontal de advertência}

Este estudo visou identificar métodos/técnicas empregados em pesquisas publicadas em forma de artigos científicos que avaliaram a eficácia comunicacional de rotulagens frontais de advertências, e estabelecer sua conformidade com etapas da comunicação de advertências adotados no C-HIP model (Communication - Human Information Processing). 
5.1 Meta-análise dos artigos sobre avaliação de rotulagem de advertência

Este estudo adotou abordagem qualitativa na análise dos métodos/ técnicas das pesquisas que compuseram o corpus dos artigos. Para estabelecer o corpus documental a ser analisado, utilizou-se os dados do documento 'Modelos de rotulagem nutricional frontal de alto conteúdo de nutrientes críticos comparado a outros modelos de rotulagem frontal nutricional: uma revisão sistemática' de Silva (2019). Este foi realizado por demanda conjunta da ANVISA e do CNPq (Conselho Nacional de Desenvolvimento Científico e Tecnológico) na chamada $\mathrm{n}^{0}{ }_{17} / 2017$. Assim, por utilizar dados primários de pesquisas anteriores que são significativas em relação ao tema em foco, considera-se que o presente estudo constitui uma meta-análise qualitativa (Bicudo, 2014).

A Revisão Sistemática sobre Rotulagem Frontal conduzida por Silva (2019) inicialmente constou de um universo de 2.171 publicações, das quais 11 foram selecionadas através de critérios de inclusão e exclusão quanto às avaliações de rótulos nutricionais frontais de advertência. Estes artigos constituem o corpus do presente estudo, e encontram-se no Anexo 1.

Para conduzir a meta-análise qualitativa dos artigos, foi inicialmente realizada a leitura sistemática e in depth de cada artigo, identificando: os rótulos testados, abordagem adotada (qualitativa/ quantitativa), dimensões e métricas avaliadas (e.g., compreensão, percepção, tempo de resposta) e local de condução da pesquisa. Em seguida, os resultados da meta-análise foram tabulados e alinhados com as etapas do C-HIP model.

\subsection{Síntese dos resultados e discussão}

Do total dos 11 artigos selecionados na revisão de Silva (2019), identificou-se que os rótulos nutricionais frontais de advertência utilizados nos artigos foram: Alertas octogonais "alto em" na cor preta $(n=7)$, alertas triangulares "alto em" na cor preta $(n=2)$, círculo vermelho "alto em" $(\mathrm{n}=2)$, aviso de saúde apenas com texto "alto em" $(n=2)$, e palavra sinal e consequência sobre retângulo amarelo $(n=1)$.

Os procedimentos identificados foram transversais, quaseexperimentos on-line utilizando questionários e escalas $(n=6)$, experimentos de compra on-line $(n=4)$, e rastreamento ocular $(n=1)$. Além disso, a maioria empregou abordagem quantitativa $(n=10)$, e apenas um estudo adotou abordagem integrada quali-quanti. Os estudos foram conduzidos no Uruguai $(n=5)$, Brasil $(n=3)$ e Canadá $(n=3)$.

Quanto às métricas e dimensões utilizadas, estas foram variadas nos testes reportados nos artigos. A incidência total das métricas nos 11 artigos foi: percepção de saudabilidade $(n=5)$, quantidade de 
açúcar do produto adquirido $(\mathrm{n}=4)$, quantidade de calorias do produto adquirido $(n=4)$, quantidade de aquisição de sódio $(n=3)$, quantidade de aquisição de gordura saturada $(n=3)$, captura de atenção e tempo de processamento $(n=2)$, frequência de consumo $(n=2)$, capacidade de diferenciação de saudabilidade dos produtos $(n=2)$, gastos totais com as compras $(n=2)$, compra de bebidas açucaradas $(n=1)$, quantidade de produtos advertências de nutrientes críticos adquiridos $(\mathrm{n}=1)$, compreensão do conteúdo nutricional e compreensão de teor de nutrientes $(n=1)$, intenções de compra $(n=1)$, emoções $(n=1)$, opinião $(n=1)$, percepção de rispidez $(n=1)$, percepção de controle/autonomia sobre as escolhas alimentares $(n=1)$.

Na sequência, os artigos de avaliação de rótulos nutricionais de advertência selecionados por Silva (2019) foram analisados, considerando as etapas do receptor presentes no C-HIP model, juntamente testes sugeridos por Wogalter, Dejoy e Laughery (1999), Young e Lovvoll (1999) e Wogalter e Dingus (1999). O diagrama a seguir apresenta uma síntese desta análise. A primeira coluna mostra as etapas do Receptor (área em verde), a segunda coluna lista os testes para avaliação de advertências, e a última lista aqueles identificados nos artigos analisados. 


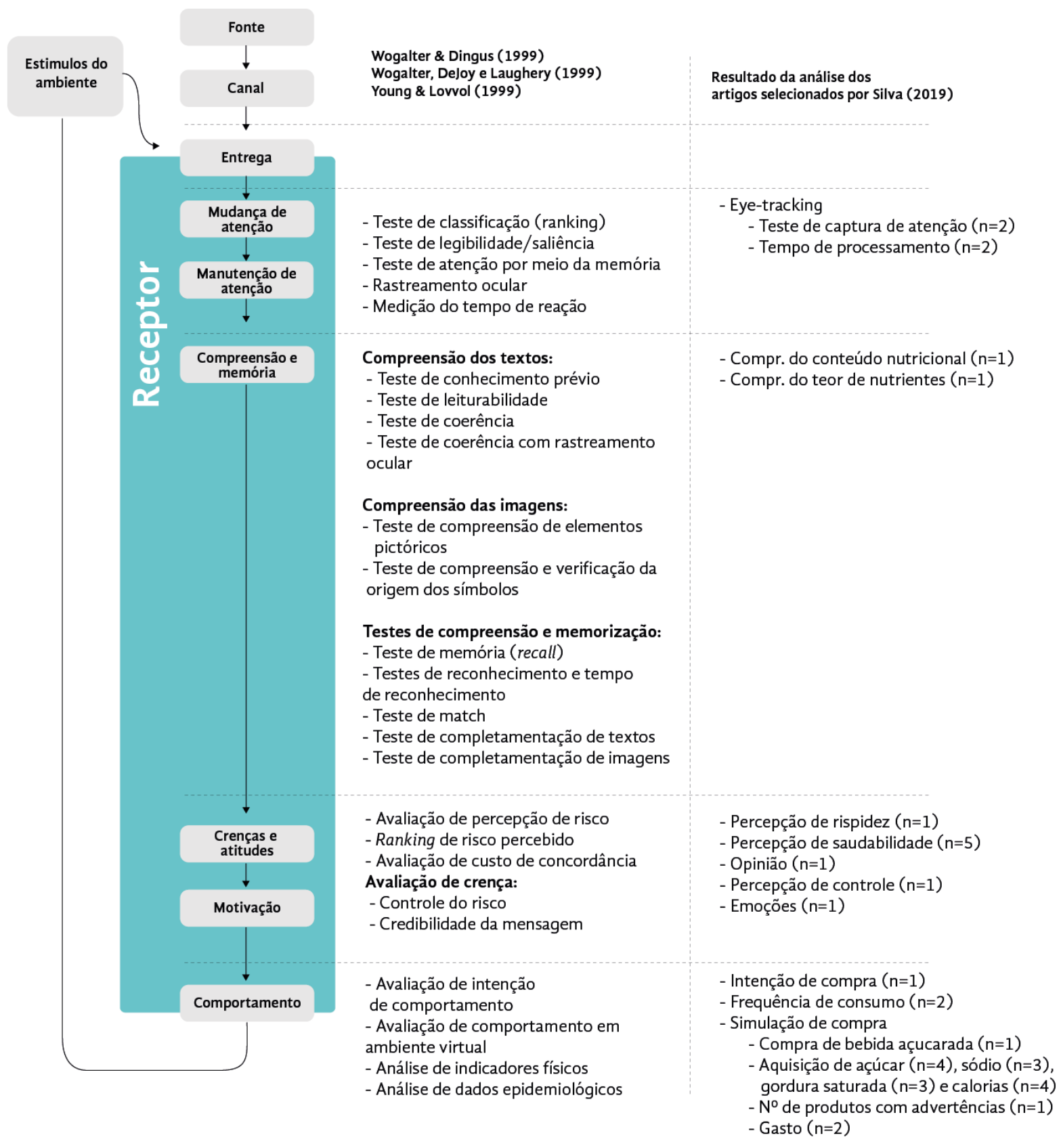

Gráfico 3 Comparativo entre técnicas e métricas dos artigos analisados no escopo do C-HIP model.

Nas etapas de Mudança de atenção e Manutenção de atenção do C-HIP Model podem ser relacionados dois testes nos artigos analisados: o teste de captura de atenção e o de tempo de processamento, ambos ocorreram em dois artigos (Arrúa et al, 2017; Ares et al, 2018) e empregaram eye-tracking. Isto mostra convergência metodológica nestes estudos. Considerando os testes recomendados por Wogalter, Dejoy e Laughery (1999), e Young e Lovvol (1999), constatou-se que apenas testes de rastreamento ocular foram incluídos nos artigos analisados, ou seja, os artigos não apresentam testes de 
2 O termo harshness usado no estudo de Acton e Hammond (2018a) é traduzido aqui como 'rispidez/rigidez', diferentemente da tradução 'agressividade' adotada por Silva (2019). classificação, legibilidade/saliência ou atenção por meio da memória (recall).

Para a etapa de compreensão do C-HIP Model podem ser relacionados dois testes ambos conduzidos em apenas um dos artigos (Khandpur et al, 2018): o de compreensão do conteúdo nutricional e o de compreensão do teor de nutrientes. Estes respectivamente verificaram o quanto os participantes entendiam o teor nutricional de certos produtos e a diferença de teor entre dois produtos similares. Portanto, não foram identificados nos artigos a condução de testes de compreensão dos textos (e.g., conhecimento prévio, leiturabilidade ou coerência com rastreio ocular), de compreensão das imagens/ símbolos (e.g., elementos pictóricos ou origem de símbolos) tão pouco testes de memória (e.g., recall, tempo de reconhecimento ou match), como recomenda a literatura aqui mencionada.

Diferentemente das etapas anteriores, para as etapas de crenças e atitudes, e motivação do C-HIP Model podem ser relacionados cinco testes conduzidos em sete artigos analisados: (a) percepção de rispidez/rigidez (harshness ${ }^{2}$ ) e (b) de controle (Acton \& Hammond, 2018a), (c) percepção de saudabilidade do produto (Arrúa et al, 2017; Khandpur et al, 2018; Machín et al, 2018a; Ares et al, 2018; Lima et al, 2018); (d) opinião geral sobre rótulos (Khandpur et al, 2018); e (e) teste sobre respostas emocionais aos rótulos (Lima et al, 2019). O primeiro teste verificou o quanto o participante considera a mensagem do rótulo ríspida e o segundo o quanto o participante acredita ter controle nas suas escolhas alimentares com o uso do rótulo nos produtos, ambos presentes em um artigo (Acton \& Hammond, 2018a). A percepção de saudabilidade do produto referiu-se ao quanto o participante acredita que um dado produto era saudável com e/ou sem a presença dos rótulos de advertência ou ainda comparando produtos entre si. Isto foi verificado em cinco dos sete artigos, o que parece indicar uma preocupação maior dos pesquisadores com esta dimensão da comunicação de mensagens dos rótulos. Apenas um estudo (Khandpur et al, 2018) investigou a opinião dos participantes em relação a quanto consideravam os rótulos úteis e a credibilidade e veracidade associadas à informação dos rótulos. As respostas emocionais aos rótulos foram investigadas também em um estudo apenas (Lima et al, 2019) em relação a como crianças se sentiriam ao comer um dado produto, usando expressões pictóricas (emojis).

Em relação às recomendações de Wogalter, Dejoy e Laughery (1999) e Young e Lovvol (1999), não foram relatados nos artigos, testes de familiaridade com o risco ou avaliação de custo de concordância. Por outro lado, pode se inferir que a avaliação da percepção de saudabilidade dos participantes nos artigos analisados implica em uma avaliação de percepção de risco. Isto, porque ao avaliar um produto como não saudável, o participante pode estar inferindo que ele apresenta algum risco a sua saúde. Vale ressaltar 
que a percepção de rispidez (harshness) verificada em um dos artigos não tem sido considerada na literatura como dimensão associada a advertências. Entretanto, é possível que a percepção de rispidez do rótulo nutricional tenha sido verificada para responder a questionamentos postos por governos e pela indústria. Por exemplo, a indústria de alimentos e bebidas costuma alegar que os rótulos nutricionais frontais de advertência são agressivos, podendo gerar 'medo' no consumidor (ARES et al, 2020; MIALON et al, 2021). Esta posição reativa talvez se deva ao conflito de interesse da indústria de alimentos e bebidas quanto à adoção de políticas públicas de promoção à saúde que interfiram no marketing e vendas de alguns de seus produtos.

Para a etapa de comportamento do C-HIP Model, podem ser relacionados três testes em seis artigos: o de intenção de compra (ARES et al, 2018), frequência de consumo (LIMA et al, 2018), e simulação de compra (ACTON \& HAMMOND, 2018b; ACTON et al, 2019; MACHÍN et al, 2017, 2018b). O primeiro teste verificou quais produtos o participante estaria disposto a comprar, o segundo, do ponto de vista dos pais, verificou qual seria a frequência ideal de consumo dos produtos com rótulos para os filhos. Já o segundo teste sobre a simulação de compra, verificou quais produtos foram comprados em um mercado virtual. Nestas compras foram enfocados: quantidade de produtos adquiridos com rótulo de advertência (ACTON \& HAMMOND, 2018b), gasto e investimento em determinadas categorias de produtos (MACHÍN et al, 2017, 2018b), e quantidade total de nutrientes críticos (açúcares, sódio, gorduras) e/ ou calorias dos produtos comprados (ACTON \& HAMMOND, 2018b; ACTON et al, 2019; MACHÍN et al, 2017, 2018b).

Em relação às recomendações da literatura em advertência, não foram relatados nos artigos a utilização de indicadores físicos ou de dados epidemiológicos para avaliação de rotulagem frontal de advertência nutricional. Entretanto, existem estudos epidemiológicos e estudos baseados em dados sobre mudança de composição dos alimentos em países como Chile no qual a rotulagem de advertência já foi implementada (e.g., REYES et al, 2020; HARGOUS et al, 2020). Estes, todavia, não constam nos artigos selecionados por Silva (2019) e aqui analisados.

\section{Principais conclusões}

O caráter qualitativo deste estudo impede generalizações quanto aos achados da meta-análise das pesquisas que avaliaram a eficácia comunicacional de rotulagens frontais de advertências. Todavia, com base nos artigos analisados é possível inferir aspectos metodológicos comuns que possam ser indicadores de tendências e de lacunas na pesquisa sobre avaliação de rotulagem frontal de advertência. Parece haver prevalência de estudos quantitativos de percepção de 
saudabilidade na área da nutrição e carência de constructos com informações qualitativas que auxiliem na interpretação de dados quantitativos de comportamento informacional quanto a advertências no âmbito da nutrição.

Além disto, de forma geral, a avaliação dos rótulos nutricionais parece enfatizar as etapas finais do processamento cognitivo de advertências. Isto pode auxiliar a identificar a eficácia dos rótulos, mas dificilmente explicará com riqueza a causalidade da eficácia. Neste sentido, questões como por exemplo: quais fatores gráficoinformacionais influenciam a comunicação de advertências e o comportamento do consumidor, ainda permanecem sem respostas. Os resultados parecem ainda apontar a necessidade de convergência metodológica na avaliação das rotulagens nutricionais de advertências, como: quais testes, dimensões e métricas são apropriados para mensurar advertência em rotulagem frontal, que se diferencia dos outros tipos de rotulagem nutricional. Portanto, é possível inferir a existência de lacunas em pesquisas na área de nutrição quanto a aspectos inerentes ao design e processamento da informação de advertência, demandando assim futuras investigações. Estas podem contribuir para uma avaliação compreensiva de rótulos frontais de advertência, adotando abordagem metodológica híbrida - combinando estudos qualitativos e quantitativos - e multidisciplinar. Além disso, futuras pesquisas podem considerar as etapas iniciais do processamento da informação de advertência, em especial as etapas de atenção e compreensão, ainda pouco investigadas no âmbito da pesquisa em rotulagem nutricional frontal de advertência.

Do ponto de vista do design da informação, investigações sobre avaliação de rotulagem frontal de advertência poderiam enfocar a etapa de atenção quanto a aspectos gráficos como: cor e contraste, visualização e localização do rótulo, distrações e ruídos do contexto gráfico e legibilidade tipográfica. A avaliação referente à etapa de compreensão, por sua vez, poderia contemplar aspectos relativos à cultura visual e familiaridade dos consumidores com a representação gráfica dos rótulos nutricionais. Vale salientar que, falhas nas etapas de atenção e compreensão podem vir a comprometer a mudança de comportamento do consumidor esperada ao final do processo. Por fim, há ainda carência de pesquisas que consideram os componentes das advertências descritos na ISO e ANSI, e seus possíveis efeitos na eficácia comunicativa de rotulagem nutricional frontal.

\section{Considerações finais}

É importante frisar que neste artigo não se pretendeu avaliar a pertinência do desenho metodológico dos estudos analisados. Mas sim, identificar quais testes estão sendo empregados nas pesquisas sobre avaliação de rotulagem nutricional de advertência e quais a literatura sobre advertência recomenda. Assim, buscou-se compartilhar 
3 Esse estudo constitui parte da tese de doutorado do primeiro autor no Programa de Pós-Graduação em Design (PPGDesign) da UFPR. possibilidades de avaliação de rotulagem nutricional de advertência, do ponto de vista do design da informação e da ergonomia com a área de nutrição.

Entretanto, este estudo apresenta algumas limitações em sua metaanálise dos artigos de avaliação de rotulagem frontal de advertência. Estas são decorrentes de não ter sido possível o acesso aos protocolos de pesquisa utilizados, o que limitou a análise dos artigos à interpretação dos procedimentos e resultados apresentados pelos seus pesquisadores. Outra limitação deve-se a alguns dos critérios de elegibilidade da revisão sistemática de Silva (2019), determinando os artigos aqui discutidos. Estes favoreceram a inclusão de estudos com abordagem quantitativa, como por exemplo ensaios clínicos randomizados (ECR), limitando a análise e discussão dos artigos aos testes empregados nestes estudos. Além disso, pode se mencionar como limitação o recorte temporal do corpus desta meta-análise, por este ser oriundo da seleção de artigos da revisão sistemática conduzida em 2019. Assim, pesquisas mais recentes não foram consideradas (e.g., TAILLIE et al, 2020; ARES et al, 2020), o que pode vir a ocorrer em futuros estudos como este. Apesar das limitações postas, acredita-se que este artigo contribui para uma visão integrada de design, ergonomia e nutrição na pesquisa de avaliação de rotulagem nutricional de advertência.

Para concluir, enfatiza-se a importância do ponto de vista do design da informação para discussão de rotulagem nutricional e tomada de decisão de políticas públicas em saúde relacionadas ao acesso e empoderamento dos cidadãos por meio da informação. Como desdobramento deste estudo está sendo desenvolvido um método de avaliação de rótulos frontais de advertência nutricional na perspectiva do design da informação ${ }^{3}$ alinhado aos preceitos das pesquisas sobre advertência.

\section{Agradecimento}

O presente trabalho foi realizado com apoio da Coordenação de Aperfeiçoamento de Pessoal de Nível Superior- Brasil (CAPES) Código de Financiamento 001. 


\section{Referências}

ACTON, R. B. et al. Taxes and front-of-package labels improve the healthiness of beverage and snack purchases: a randomized experimental marketplace. International Journal of Behavioral Nutrition and Physical Activity, v. 16, n. 1, p. 46, 2019.

ACTON, R. B.; HAMMOND, David. Do Consumers Think Front of Package "High in" Warnings are Harsh or Reduce their Control? A Test of Food Industry Concerns. Obesity, v. 26, n. 11, p. 1687-1691, 2018.

ANSI z535p4-2007 - American National Standard for products Safety Signs and Labels. 2007

ANVISA. GERÊNCIA DE ALIMENTOS. Relatório Preliminar de Análise de Impacto Regulatório sobre Rotulagem Nutricional. 2018. Disponível em: $<$ https://pesquisa.anvisa.gov.br/upload/surveys/981335/files/Análise\%20 de\%2oImpacto\%2oRegulatório\%2osobre\%2oRotulagem\%2oNutricional.pdf> Acesso em 4 de maio de 2021.

ARES, G. et al. Influence of label design on children's perception of two snack foods: comparison of rating and choice-based conjoint analysis. Food Qual Prefer 53: 1-8. 2016.

ARES, G. et al. Argumentos de la industria alimentaria en contra del etiquetado frontal de advertencias nutricionales en Uruguay. Revista Panamericana de Salud Pública, v. 44, p. e20, 2020.

ARES, G. et al. Comparative performance of three interpretative front-of-pack nutrition labelling schemes: Insights for policy making. Food Quality and Preference, v. 68, p. 215-225, 2018.

ARRÚA, A. et al. Warnings as a directive front-of-pack nutrition labelling scheme: Comparison with the Guideline Daily Amount and traffic-light systems. Public health nutrition, v. 20, n. 13, p. 2308-2317, 2017.

BICUDO, M. A. V. Meta-análise: seu significado para a pesquisa qualitativa. Revista Eletrônica de Educação Matemática, v. 9, p. 7-20, 2014.

BORGMEIER I, WESTENHOEFER J. Impact of different food label formats on healthiness evaluation and food choice of consumers: a randomizedcontrolled study. BMC Public Health. 2009; 9:184.

COWBURN, G.; STOCKLEY, L. Consumer understanding and use of nutrition labelling: a systematic review. Public health nutrition, v. 8, n. 1, p. 21$28,2005$.

EDWORTHY, J. (Ed.). Warning design: A research prospective. CRC Press, 1996.

EDWORTHY, J.. An integrative approach to warnings research. In: Proceedings of the Human Factors and Ergonomics Society Annual Meeting. Sage CA: Los Angeles, CA: SAGE Publications, 2000. p. 770-773.

EUFIC (2017) Global Update on Nutrition Labelling: The 2017 Edition. Brussels: EUFIC.

EMRICH, T. E.; ARCAND, J.; L'ABBÉ, M. R. Front-of-pack nutrition labelling systems: a missed opportunity? Canadian Journal of Public Health, v. 103, n. 4, p. e260-e262, 2012.

FALKENBURGER, P.; SCOZ, M. Diretrizes projetuais para sistemas de advertência em embalagens de alimentos ultraprocessados. InfoDesign: Revista Brasileira de Design da Informação, v. 16, n. 3, 2019. 
FLABEL, Food Labelling to Advance Better Education for Life. Final webinar. 2012. Disponível em http://flabel.org/en/News/FLABEL-final-webinar/, acesso em: 18/8/2020.

FOOD AND AGRICULTURE ORGANIZATION (FAO). Cúpula Mundial de Alimentação (Declaração de Roma Sobre a Segurança Alimentar Mundial \& Plano de Ação da Cúpula Mundial da Alimentação). 1996.

GRUNERT, K. G.; WILLS, J. M. A review of European research on consumer response to nutrition information on food labels. Journal of public health, $\mathrm{v}$. 15, n. 5, p. 385-399, 2007.

HARGOUS, C. V. et al. Consumption of non-nutritive sweeteners by preschoolers of the food and environment Chilean cohort (FECHIC) before the implementation of the Chilean food labelling and advertising law. Nutrition journal, v. 19, n. 1, p. 1-11, 2020.

HAWLEY, K. L. et al. The science on front-of-package food labels. Public health nutrition, v. 16, n. 3, p. 430-439, 2013.

HERSEY, J. C. et al. Effects of front-of-package and shelf nutrition labeling systems on consumers. Nutrition reviews, v. 71, n. 1, p. 1-14, 2013.

HODGKINS, C. et al. Understanding how consumers categorise nutritional labels: a consumer derived typology for front-of-pack nutrition labelling. Appetite, v. 59, n. 3, p. 806-817, 2012.

INSTITUTO BRASILEIRO DE DEFESA DO CONSUMIDOR (IDEC). O rótulo pode ser melhor. Revista do Idec. 2016; 208:16-20.

INSTIUTO BRASILEIRO DE DEFESA DO CONSUMIDOR (IDEC) e UNIVERSIDADE FEDERAL DO PARANÁ (UFPR). Aprimoramento da informação nutricional nos rótulos de alimentos no Brasil - Proposta apresentada à Agência Nacional de Vigilância Sanitária (Anvisa) como conclusão do Grupo de Trabalho de Rotulagem Nutricional. 2017

INFORMAS. Protocol: Food Labelling Module., 6. dez. 2017.. The University of Auckland. Disponível em: <https://auckland.figshare.com/articles/journal_ contribution/INFORMAS_Protocol_Food_Labelling_Module/5673643/1>. Acesso em: 18/8/2020.

INSTITUTO DE NUTRICIÓN Y TECNOLOGÍA DE ALIMENTOS (INTA). Universidad de Chile. Estudio sobre evaluación de mensajes de advertencia de nutrientes críticos en el rotulado de alimentos: Informe final. 2012.

INTERNATIONAL ORGANIZATION FOR STANDARDIZATION (ISO). 38641: Símbolos gráficos - Cores e sinais de segurança - Parte 1: Princípios de design para sinais e marcações de segurança. 2013

INTERNATIONAL ORGANIZATION FOR STANDARDIZATION (ISO). 7001: Graphical symbols - Public information symbols. 3 ed. Geneva, 2018.

INTERNATIONAL ORGANIZATION FOR STANDARDIZATION (ISO). 9186-1: Graphical symbols - Test methods. Second edition ed. Geneva, 2014.

KANTER, R.; VANDERLEE, L.; VANDEVIJVERE, S. Front-of-package nutrition labelling policy: global progress and future directions. Public Health Nutrition, v. 21, n. 8, p. 1399-1408, 2018.

KELLY B. et al. Consumer testing of the acceptability and effectiveness of frontof-pack food labelling systems for the Australian grocery market. Health Promot Int. 2009;24(2):120-9. 
KHANDPUR, $\mathrm{N}$ et al. Choosing a front-of-package warning label for Brazil: A randomized, controlled comparison of three different label designs. Food Research International, v. 121, p. 854-861, 2018.

LAUGHERY, K. R.; HAMMOND, A. Overview. In: Wogalter MS, DeJoy DM, Laughery KR (eds) Warnings and risk communication. Taylor \& Francis, Philadelphia, pp 9-11. 1999

LAUGHERY, K. R. Safety communications: warnings. Applied ergonomics, v. 37, n. 4, p. 467-478, 2006.

LAUGHERY, K. R.; WOGALTER, Michael S. A three-stage model summarizes product warning and environmental sign research. Safety science, v. 61, p. 3-10, 2014.

LEHTO, M. R. Designing warning signs and labels: a theoretical/scientific framework. International Journal for Consumer and Product Safety, v. 3, n. 4, p. 205-216, 1996.

LEHTO, M. R. Designing warning signs and warning labels: part II-scientific basis for initial guidelines. International Journal of Industrial Ergonomics, v. 10, n. 1-2, p. 115-138, 1992.

LIMA, M. et al. Can front-of-pack nutrition labeling influence children's emotional associations with unhealthy food products? An experiment using emoji. Food Research International, v. 120, p. 217-225, 2019.

MIALON, M. et al. Arguments used by trade associations during the early development of a new front-of-pack nutrition labelling system in Brazil. Public Health Nutrition, v. 24, n. 4, p. 766-774, 2021.

MINISTERIO DE SALUD (MINSAL). Gobierno de Chile. Feedback. Informe de investigación "Evaluación de mensajes de advertencia en el etiquetado de alimentos mediante grupos focales". Santiago; 2009

MONT'ALVÃO, C. Designs de advertência para embalagens. 2AB, 2002.

MONTEIRO, C. A.; et al. A new classification of foods based on the extent and purpose of their processing. Cadernos de saúde publica, v. 26, n. 11, p. 20392049, 2010.

OLIVEIRA, L.L; BOCCHINI, M. O. Legibilidade visual para informação nutricional em rótulos de alimentos. Blucher Design Proceedings, v. 2, n. 2, p. 1-10, 2015.

PAHO. Ultra-processed food and drink products in Latin America: Trends, impact on obesity, policy implications. Pan American Health Organization World Health Organization: Washington, DC, USA, p. 1-58, 2015.

PARSONS, Stuart O.; SEMINARA, Joseph L.; WOGALTER, Michael S. A summary of warnings research. Ergonomics in Design, v. 7, n. 1, p. 21-31, 1999

PETTERSSON, R. Basic ID-concepts. Institutet for infology, 2020.

POPKIN, B.M.; ADAIR, L. S.; NG, S.W. Global nutrition transition and the pandemic of obesity in developing countries. Nutrition reviews, v. 70, n. 1, p. 3-21, 2012.

REYES, M. et al. Development of the Chilean front-of-package food warning label. BMC public health, v. 19, n. 1, p. 906, 2019.

REYES, M. et al. Changes in the amount of nutrient of packaged foods and beverages after the initial implementation of the Chilean Law of Food Labelling and Advertising: A nonexperimental prospective study. PLoS medicine, v. 17, n. 7, p. e1003220, 2020. 
ROGERS, W.A.; LAMSON, N.; ROUSSEAU, G. K. Warning research: An integrative perspective. Human Factors, v. 42, n. 1, p. 102-139, 2000.

SILVA, Thales Brendon Castano. Modelos de rotulagem nutricional frontal de alto conteúdo de nutrientes críticos comparado a outros modelos de rotulagem frontal nutricional: uma revisão sistemática. 2019

SPINILLO, C. G. Challenging Titans, proposing the triangle as a front of packaging warning nutrition labeling for Brazil. Selected Readings of the 8th Information Design International Conference. 2019

TALATI, Z; Et al. Consumers' Perceptions of Five Front-of-Package Nutrition Labels: An Experimental Study Across 12 Countries. Nutrients, v. 11, n. 8, p. 1934, 2019.

VAN DER BEND, D. LM; LISSNER, L. Differences and similarities between frontof-pack nutrition labels in Europe: A comparison of functional and visual aspects. Nutrients, v. 11, n. 3, p. 626, 2019.

VAN KLEEF E, DAGEVOS H. The Growing Role of Front-of-Pack Nutrition Profile Labeling: A Consumer Perspective on Key Issues and Controversies. Crit Rev Food Sci Nutr 2015; 55(3): 291-303. 2015

WHO/FAO. Codex Alimentarius: etiquetado de los alimentos. 5. ed. Roma: OMSFAO, 2017.

WOGALTER, M. S. (Ed.). Handbook of warnings. CRC Press, 2006.

WOGALTER, M. S. Communication-Human Information Processing (C-HIP) Model in Forensic Warning Analysis. In: Congress of the International Ergonomics Association. Springer, Cham, 2018. p. 761-769.

WOGALTER, M. S. et al. Warning design. Information Design: Research and Practice, p. 331-348, 2017.

WOGALTER, M. S. Factors that influence the effectiveness of warning signs and labels. MORAES, Anamaria de; AMADO, Giuseppe. Coletânea de palestras de convidados internacionais e nacionais: Ergodesign e USIHC. Rio de Janeiro: FAPERJ, p. 25-36, 2004.

WOGALTER, M.S.; DINGUS, T. A. Methodological techniques for evaluating behavioral intentions and compliance. Warnings and risk communication, $\mathrm{p}$. 53-81, 1999.

WOGALTER, M. S.; DEJOY, D.; LAUGHERY, K. R. Intermediate Processing Stages: Methodological Considerations for Research on Warnings. In: Warnings and Risk Communication. CRC Press, 1999. p. 38-63.

WOGALTER, M. S.; DEJOY, D.; LAUGHERY, K.R. (Ed.). Warnings and risk communication. CRC Press, 1999.

WOGALTER, M. S.; LAUGHERY, Kenneth R. Warning! Sign and label effectiveness. Current Directions in Psychological Science, v. 5, n. 2, p. 3337, 1996.

WOGALTER, M. S.; MAYHORN, C. B. Warning design. In. BLACK, A. et al. Information design, research and practice. $1^{\mathrm{a}}$ edição, New York e London, editora Routledge. p. 331-348. 2017

WOGALTER, M. S. Forensic human factors and ergonomics: case studies and analyses. CRC Press, 2018

WOGALTER, M. S.; CONZOLA, V. C, SMITH-JACKSON, T, L. Research-based guidelines for warning design and evaluation. Applied Ergonomics 332002. pg 219-230 
WORLD CANCER RESEARCH FUND INTERNATIONAL. Building momentum: Lessons on implementing a robust front of pack food label. 2019.

YOUNG, S. L.; LOVVOLL, D. R. Intermediate Processing Stages: Methodological Considerations for Research on Warnings. Warnings and Risk Communication, p. 23, 2005.

\section{Sobre os autores:}

\section{Carlos Felipe Urquizar Rojas}

cf.u.rojas@gmail.com

Professor no Departamento de Design da Universidade de Joinville

(UNIVILLE)

Doutorando no Programa de Pós-graduação em Design da Universidade

Federal do Paraná

Membro do LabDSI-Laboratório de Design de Sistemas de Informação/UFPR Rua Gen. Carneiro, 400 - Edf. Dom Pedro I, sala 830 - Centro, Curitiba-PR

\section{Carla Galvão Spinillo}

cgspin@gmail.com

Professora do Programa de Pós-Graduação em Design/Departamento de Design da Universidade Federal do Paraná

Coordenadora do LabDSI-Laboratório de Design de Sistemas de Informação/ UFPR

Rua Gen. Carneiro, 400 - Edf. Dom Pedro I, sala 830 - Centro, Curitiba-PR

Artigo recebido em/Submission date 28/02/2021

Artigo aprovado em/Approvement date 17/05/2021 


\section{ANEXO 1}

Artigos selecionados na revisão de Silva (2019)

Acton RB, Hammond D. Do Consumers Think Front-of-Package "High in" Warnings are Harsh or Reduce their Control? A Test of Food Industry Concerns. Obesity. ${ }^{2018} \mathrm{a}$ Disponível em: http://dx.doi.org/10.1002/oby.22311

Acton RB, Hammond D. The impact of price and nutrition labelling on sugary drink purchases: Results from an experimental marketplace study. Appetite. 2018b Disponível em: http://dx.doi.org/10.1016/j.appet.2017.11.089

Acton RB, Jones AC, Kirkpatrick SI, Roberto CA, Hammond D. Taxes and front-of-package labels improve the healthiness of beverage and snack purchases: a randomized experimental marketplace. International Journal of Behavioral Nutrition and Physical Activity. 2019 Disponível em: http://dx.doi.org/10.1186/s12966-019-0799-0

Arrúa A, Machín L, Curutchet MR, Martínez J, Antúnez L, Alcaire F, Giménez A, Ares G. Warnings as a directive front-of-pack nutrition labelling scheme: comparison with the Guideline Daily Amount and traffic- light systems. Public Health Nutrition. 2017 Disponível em: http://dx.doi.org/10.1017/S1368980017000866

Khandpur N, de Morais Sato P, Mais LA, Bortoletto Martins AP, Spinillo CG, Garcia MT, Rojas CFU, Jaime PC. Are Front-of-Package Warning Labels More Effective at Communicating Nutrition Information than TrafficLight Labels? A Randomized Controlled Experiment in a Brazilian Sample. Nutrients. 2018 Disponível em: http://dx.doi.org/10.3390/nu10060688

Lima M, de Alcantara M, Martins IBA, Ares G, Deliza R. Can front-of-pack nutrition labeling influence children's emotional associations with unhealthy food products? An experiment using emoji. Food Research International. 2019

Disponível em: http://dx.doi.org/10.1016/j.foodres.2019.02.027

Machín L, Aschemann-Witzel J, Curutchet MR, Giménez A, Ares G. Traffic Light System Can Increase Healthfulness Perception: Implications for Policy Making. Jornal of Nutrition Education Behavior. 2018a Disponível em: http://dx.doi.org/10.1016/j.jneb.2018.03.005

Machín L, Aschemann-Witzel J, Curutchet MR, Giménez A, Ares G. Does front-of-pack nutrition information improve consumer ability to make healthful choices? Performance of warnings and the traffic light system in a simulated shopping experiment. Appetite. $2018 \mathrm{~b}$ Disponível em: http://dx.doi.org/10.1016/j.appet.2017.10.037

Machín L, Arrúa A, Giménez A, Curutchet MR, Martínez J, Ares G. Can nutritional information modify purchase of ultra-processed products? Results from a simulated online shopping experiment. Public Health Nutrition. 2017 http://dx.doi.org/10.1017/S1368980017001185

Ares G, Varela F, Machin L, Antúnez L, Giménez, Curutchet MR, Witzel JA. Comparative performance of three interpretative front-of-pack nutrition 
labelling schemes: Insights for policy making. Food Quality Preference.

2018

Disponível em: https://linkinghub.elsevier.com/retrieve/pii/

$\underline{\text { So950329318300193 }}$

Lima M, Ares G, Deliza R. How do front of pack nutrition labels affect healthfulness perception of foods targeted at children? Insights from Brazilian children and parents. Food Quality Preference. 2018 Disponível em: https://linkinghub.elsevier.com/retrieve/pii/ $\underline{\text { So950329317302367 }}$ 